Published in final edited form as:

Organometallics. 2004 August 16; 23(17): 4003-4005.

\title{
Nitro and Nitroso Metathesis Reactions with Monomeric Zirconium Imido Complexes
}

\author{
Suzanne A. Blum and Robert G. Bergman* \\ Center for New Directions in Organic Synthesis, Department of Chemistry, University of California, \\ Berkeley, California 94720
}

\section{Summary}

The bis(cyclopentadienyl)(tert-butylimido)zir-conium complex $\mathbf{1}$ undergoes ambient-temperature metathesis reactions with nitro- and nitrosoarenes, providing a rare nonphotochemical synthesis of cis-azoxy and cis-azo compounds, respectively. 2-Nitro-2-methylpropane also undergoes metathesis to give trans-(tert-butylazoxy)-2-methylpropane. This reaction was studied kinetically, and the rate was found to be first order in both $\mathbf{1}$ and substrate and inversely proportional to the concentration of tetrahydrofuran, with activation parameters $\Delta \mathrm{H}^{\ddagger}=15 \pm 2 \mathrm{kcal} \mathrm{mol}^{-1}$ and $\Delta \mathrm{S}^{\ddagger}=-26 \pm 3 \mathrm{cal} \mathrm{mol}^{-1}$ $\mathrm{K}^{-1}$.

During our investigations of imidozirconocene-mediated epoxide opening reactions, ${ }^{1}$ we were surprised to find that $p$-nitrostyrene oxide failed to undergo the expected epoxide opening but, rather, underwent an alternative reaction of the nitro group. We now report a more detailed study of the reaction of $\mathrm{Cp}_{2} \mathrm{Zr}=\mathrm{N}-t$-Bu-(THF) (1) ${ }^{2,3}$ with $p$-nitrotoluene, which has revealed a metathesis reaction between the $\mathrm{N}=\mathrm{O}$ and $\mathrm{Zr}=\mathrm{N}-t-\mathrm{Bu}$ functionalities, generating the very reactive cis-(tert-butylazoxy)toluene (cis-2) and $\left[\mathrm{Cp}_{2} \mathrm{Zr}=\mathrm{O}\right]_{n}$ (3) (Scheme 1). Direct synthesis of acyclic cis azoxy compounds is challenging; therefore, the cis isomer is usually made by chemical synthesis of the trans isomer, followed by photoisomerization. ${ }^{4}$ To our knowledge, the transformation in Scheme 1 represents a rare example of a transition-metal-mediated [2+ 2] metathesis reaction involving a nitro group and direct chemical synthesis of a cis azoxy compound. Herein we discuss the scope and mechanism of this novel process, as well as its extension to nitroso compounds.

The addition of imido complex $\mathbf{1}$ to $p$-nitrotoluene resulted in rapid formation of cis-2 and oxozirconocene. The product $c i s-2$ was initially identified by the distinctive upfield resonances of its ortho protons in the ${ }^{1} \mathrm{H}$ NMR spectrum (45\% NMR yield). ${ }^{5}$ Over several hours cis-2 isomerized quantitatively to trans-2. The oxozir-conocene coproduct formed through this metathesis was efficiently trapped under the reaction conditions with chlorotrimethylsilane (TMSCl) to give complex 4.6

Interestingly, the reduced trans-tert-butylazotoluene (5) is formed as a byproduct $\left(22 \%{ }^{1} \mathrm{H}\right.$ NMR yield), with no cis-5 observed. (Alkylazo)aryl compounds have been observed previously as byproducts in the synthesis of (alkylazoxy)aryl compounds by the reaction of Grignard reagents with nitroaromatic compounds. 7,8 We considered the possibility that imido complex 1 reacted with the newly formed azoxy compound $\mathbf{2}$ to form $\mathbf{5}$. Azoxy compound $\mathbf{2}$, however, was found to be stable to the presence of excess imido complex $\mathbf{1}$ on the time scale of the

\footnotetext{
* To whom correspondence should be addressed. E-mail: bergman@ @chem.berkeley.edu..

Supporting Information Available: Text and figures giving experimental procedures, kinetic data, and analysis. This material is available free of charge via the Internet at http://pubs.acs.org.
} 
reaction. Therefore, it seemed that another pathway accounted for formation of $\mathbf{5}$, possibly through the intermediacy of nitroso or azodioxy (nitroso dimer) compounds (vide infra).

Further investigation showed that imido complex 1 also underwent metathesis with 2-methyl-2nitropropane to give trans-(tert-butylazoxy)-2-methylpropane (trans-6; $95 \%{ }^{1} \mathrm{H}$ NMR yield) (Scheme 2). This reaction was notably slower than the reactions with nitroarenes, requiring 2 days to reach complete conversion at ambient temperature. In this case, no cis intermediate was observed. ${ }^{9}$

The more reactive nitroso group displayed metathesis reactivity similar to that of the nitro group. Transition-metal-mediated metathesis reactions of nitroso compounds are known, involving both alkylidene ${ }^{10}\left(\mathrm{CR}_{2}\right.$ transfer) and imido (NR transfer) complexes. ${ }^{11}$ However, while several of these alkylidene reactions proceed from isolable complexes, prior to this account a metathesis reaction proceeding from a fully characterized imido complex had not been studied. Nitrosobenzene reacted cleanly with imido complex 1 to give cis-(tert-butylazo)benzene (cis-7) (Scheme 3). The compound cis-7a was identified by the distinctive upfield resonances of its ortho protons in the ${ }^{1} \mathrm{H}$ NMR spectrum ${ }^{5}$ and its isomerization to trans-7a over several hours (>95\% NMR yield). The electron-rich $p$-(dimethylamino)nitrosobenzene also reacted cleanly ( $>95 \%$ NMR yield). In this case, the cis to trans isomerization proceeded rapidly, with $13 \%$ trans-7b already present at the earliest monitoring time (4 min) and with quantitative isomerization after $40 \mathrm{~min}$. Addition of imido complex 1 to 2-nitroso-2methylpropane in the presence of TMSCl led to formation of $\mathbf{3}$, identified by its trapping product 4; however, the expected 2,2'-azobis(2-methylpropane) co-product was not observed. 12

The reaction of $\mathbf{1}$ with 2-methyl-2-nitropropane to give trans-6 and $\mathbf{4}$ was studied kinetically under pseudo-first-order conditions. The disappearance of starting complex $\mathbf{1}$ and appearance of both trans- $\mathbf{6}$ and $\mathbf{4}$ were monitored by ${ }^{1} \mathrm{H}$ NMR spectroscopy over the temperature range $45.0-74.5^{\circ} \mathrm{C}$. The reaction exhibited first-order kinetics with respect to both 1 and 2-methyl-2nitropropane. We report rate constants $k_{\mathrm{obsd}}$, independent of the concentrations of 2-methyl-2nitropropane and THF, which were used in excess to establish flooding conditions: $k_{\text {obsd }}=$ $0.00043 \mathrm{~s}^{-1}\left(45.0^{\circ} \mathrm{C}\right), k_{\mathrm{obsd}}=0.00076 \mathrm{~s}^{-1}\left(56.0^{\circ} \mathrm{C}\right), k_{\mathrm{obsd}}=0.0016 \mathrm{~s}^{-1}\left(64.5^{\circ} \mathrm{C}\right), k_{\text {obsd }}=$ $0.0034 \mathrm{~s}^{-1}\left(74.5^{\circ} \mathrm{C}\right) .{ }^{13}$ The rate was zero order in the concentration of trapping agent [TMSCl] and was inversely proportional to the concentration of THF. Furthermore, trans-6 and $\mathbf{4}$ formed at equal rates, concomitant with the disappearance of imido complex $\mathbf{1}$, which precludes the possibility that the concentration of an intermediate builds up significantly. Rates measured over this temperature range gave activation parameters $\Delta H^{*}=15 \pm 2 \mathrm{kcal} \mathrm{mol}^{-1}$ and $\Delta S^{\ddagger}=$ $-26 \pm 3 \mathrm{cal} \mathrm{mol}^{-1} \mathrm{~K}^{-1}$, corresponding to a free energy of activation $\Delta G^{\ddagger}=24 \pm 3 \mathrm{kcal} \mathrm{mol}^{-1}$ at $60.5^{\circ} \mathrm{C}$.

The contribution of the initial dissociation of THF from imido complex 1 to the overall activation energy was examined next. The rate of exchange of bound and free THF (Scheme 4) was measured by ${ }^{1} \mathrm{H}$ NMR spectroscopy, revealing $k_{\mathrm{obsd}}=240 \mathrm{~s}^{-1}$ at $60.5^{\circ} \mathrm{C}$, which corresponds to a free energy of activation $\Delta G^{\dagger}=16 \mathrm{kcal} \mathrm{mol}^{-1}$. This value is consistent with the establishment of a rapid equilibrium between imido complex $\mathbf{1}$ and coordinatively unsaturated imido complex $\mathbf{8}$, which, in the presence of 2-methyl-2-nitropropane, undergoes rate-limiting metathesis.

A competition experiment between $p$-(dimethylamino)nitrosobenzene and nitrosobenzene provided further mechanistic insight. When 1 equiv of imido complex 1 was allowed to react with a mixture of 2 equiv of $p$-(dimethylamino)nitrosobenzene and 2 equiv of nitrosobenzene at ambient temperature, formation of $\mathbf{7 b}$ was favored modestly over formation of $\mathbf{7 a}(\mathbf{7 b} \mathbf{\mathbf { 7 }} \mathbf{\mathbf { a }}=$ 69: 31). This modest preference is consistent with low activation barriers for reaction with 
either substrate, in contrast to the higher barrier observed for the reaction of 1 with 2-methyl-2nitropropane.

On the basis of the [2+2] reactivity of imido complex 1 with alkenes and alkynes to give isolable metallacyclobutane and -butene complexes, ${ }^{3}$ respectively, and with aldehydes to give likely oxametallacyclobutane intermediates, ${ }^{14}$ we consider that the nitro and nitroso metatheses may also proceed through [2+2] cycloadditions, in this case to give diazaoxametallacyclobutanes (9) (Scheme 5). Retrocycloaddition in the opposite sense then leads to the observed products.

In conclusion, imido complex $\mathbf{1}$ undegoes metathesis reactions with arylnitro and arylnitroso compounds to give cis-azoxy and cis-azo compounds, respectively. 2-Methyl-2-nitropropane also undergoes metathesis, yielding trans-(tert-butylazoxy)butane. This represents a rare transition-metal-mediated [2+2] metathesis reaction of nitro compounds and a rare example of a transition-metal-mediated metathesis reaction of nitroso compounds that proceeds from a fully characterized imido complex. Mechanistic credence is therefore lent to the presence of imido complexes as intermediates in other known nitroso metathesis reactions.

\section{Supplementary Material}

Refer to Web version on PubMed Central for supplementary material.

\section{Acknowledgements}

This work was supported by the NIH through Grant No. GM-25459. The Center for New Directions in Organic Synthesis is supported by Bristol-Meyers Squibb as a Sponsoring Member and Novartis as a Supporting Member.

\section{References}

1. Blum SA, Walsh PJ, Bergman RG. J Am Chem Soc 2003;125:14276. [PubMed: 14624566]

2. Walsh PJ, Hollander FJ, Bergman RG. J Am Chem Soc 1988;110:8729.

3. Walsh PJ, Hollander FJ, Bergman RG. Organometallics 1993;12:3705.

4. Taylor KG, Riehl T. J Am Chem Soc 1972;94:250.An alternative method for the synthesis of tertbutylazoxybenzene involves addition of lithium tert-butylamide to nitrobenzene; however, the trans product is usually observed under those conditions. ${ }^{7,8}$

5. a Ege SN, Sharp RR. J Chem Soc B 1971:2014. b Snyder JP, Bandurco VT, Darack F, Olsen H. J Am Chem Soc 1974;96:5158.

6. Hanna TA, Baranger AM, Bergman RG. J Org Chem 1996;61:4532. [PubMed: 11667377]

7. Shepelev EV, Kostikova NN, Dzhetigenov BA, Kalinin AV. Bull Acad Sci USSR Div Chem Sci (Engl Transl) 1991;40:1291.Izv. Akad. Nauk SSSR Ser. Khim. 1991, 6, 1452

8. Apasov ET, Dzhetigenov BA, Strelenko YA, Kalinin AV, Tartakovskii VA. Bull Acad Sci USSR Div Chem Sci (Engl Transl) 1991;40:1234.Izv. Akad. Nauk SSSR Ser. Khim. 1991, 6, 1394

9. The reactions of imido complex 1 with nitromethane, 2 -nitropropane, and $\beta$-nitrostyrene generated a variety of products, none corresponding to the desired metathesis pathway.

10. Pilato RS, Williams GD, Geoffroy GL, Rheingold AL. Inorg Chem 1988;27:3665.

11. Herndon JW, McMullen LA. J Organomet Chem 1989;368:83.

12. Azo-2-methylpropane was found to be stable in the presence of excess 1, implying that azo-2methylpropane likely does not form and then decompose by reaction with 1 .

13. We estimate the error to be $\pm 0.0001 \mathrm{~s}^{-1}$ at $64.5^{\circ} \mathrm{C}$, on the basis of a triplicate run.

14. Lee SY, Bergman RG. J Am Chem Soc 1996;118:6396. 


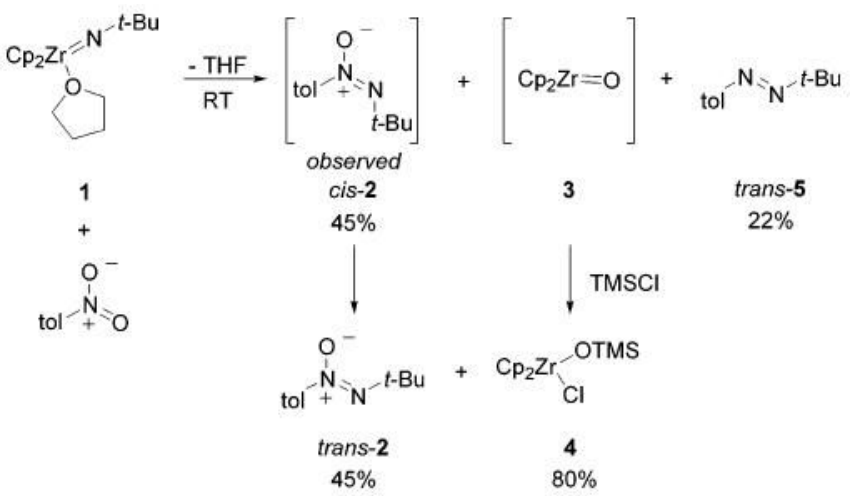

Scheme 1.

Metathesis Reaction between 1 and $p$-Nitrotoluene 


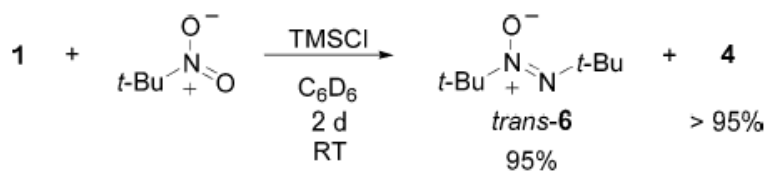

Scheme 2.

Metathesis Reaction between 1 and Methyl-2-nitropropane 


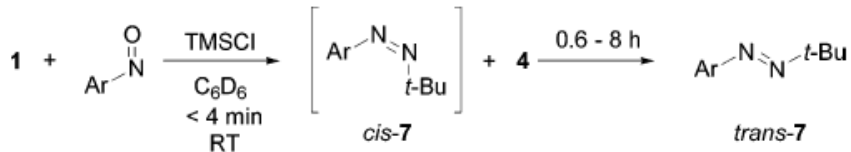

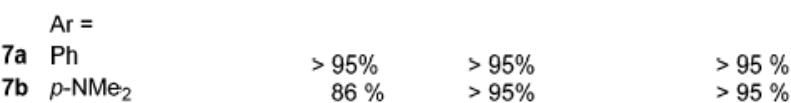

Scheme 3.

Metathesis Reaction between 1 and Nitrosoarenes 


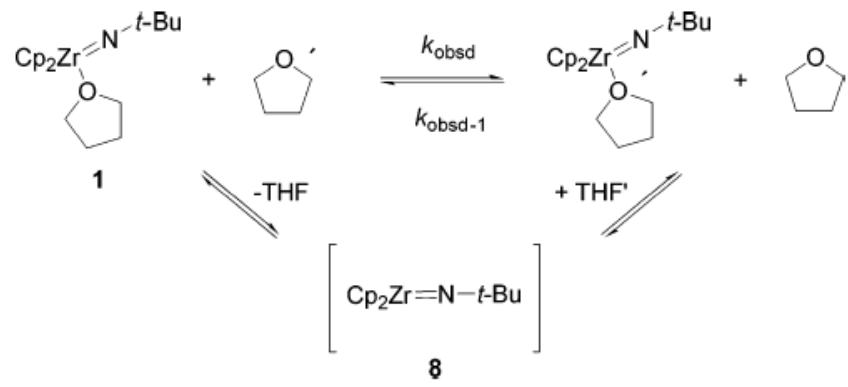

Scheme 4.

Exchange of Bound and Free THF 


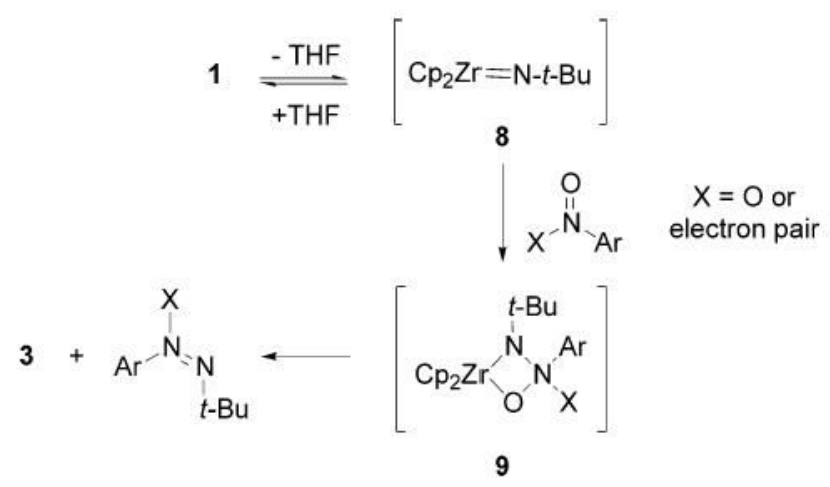

Scheme 5.

Proposed Mechanism of Metathesis Reactions 